\title{
Assessment of Life style for Elderly patient with osteoporosis in Beni-Suef University Hospital
}

\section{Sherieen Sayied Matoley ${ }^{1}$, Kamar Samieh Khader ${ }^{2,3}$, Eman El- Sherbieny ${ }^{3}$}

${ }^{1}$ Department of Medical Surgical Nursing, Faculty of Nursing, Beni-Suef University, Egypt

${ }^{2}$ Beni-Suef University Hospital, Faculty of Medicine, Beni-Suef University, Egypt

${ }^{3}$ Department of Community Health Nursing Faculty of Nursing, Beni-Suef University, Egypt Email: tel

\begin{abstract}
Background Osteoporosis related fracture is one of the leading causes of significant morbidity and disability in elderly patients. Aim of study: the study aimed to assess of life style for elderly with osteoporosis in Beni-Suef university hospital. Subjects and methods: A descriptive design was used to achieve the aim of the current study. The study was conducted in outpatient clinic of orthopedic \& rehabilitation clinic at Beni-Suef University Hospital. Convenient sample was used for this study; include all available elderly patients in outpatient clinic of orthopedic \& rehabilitation clinic at Beni-Suef University Hospital. Three tools were used in the current study as the following; Patient assessment tool, Patient assessment tool, and Life style assessment tool. Results: More than half $(61.1 \%)$ of elderly people with osteoporosis had $60-75$ year. Nearly three quarters $(70.8 \%)$ of them were male. There was a statistically significant relation between patients' total knowledge and their age, residences, and educational level. There was a statistically significant relation between patients' lifestyle and their age, marital status, residences, and educational level. Conclusion and recommendations: Majority of elderly people with osteoporosis had unsatisfactory total knowledge regarding osteoporosis. Majority of elderly people with osteoporosis had negative total lifestyle scores with osteoporosis. There was a positive correlation between patients' total knowledge and their lifestyle. Periodic assessment for elderly with osteoporosis in Beni-Suef university hospital, Help elderly to enhance life style in Beni-Suef university hospital, Provide training for nurses with elderly with osteoporosis in Beni-Suef university hospital to support patients.
\end{abstract}

Keywords: Elderly, Life style, Osteoporosis.

Receive Date : 3/8/2021

Accept Date: $25 / 8 / 2021$

Publish Date : $1 / 1 / 2022$

\section{Introduction}

Elderly people are defined by the United Nations as a person who is over 60 years of age. However, families and communities often use other socio-cultural referents to define age, including family status (grandparents),physical appearance, or age-related health conditions(1).The consequences of age growing projected many health problems as fracture, Vitamin D deficiency and osteoporosis. Fractures often result in devastating consequences. Approximately $24 \%$ of hip fracture patients aged $\geq 50$ years die during the year following their fracture(2). 
Vitamin D deficiency is common in older people, particularly those who are housebound or live in a care home, with limited sunlight exposure, so dietary vitamin D supplements may be necessary (3).

Lifestyle advice to reduce the risk of falls and fractures should be offered to all older patients irrespective of a diagnosis of osteoporosis. (4).

Osteoporosis has traditionally been diagnosed using dual energy X-ray absorptiometry (DXA), typically at the spine and hip. DXA is a non-invasive technique, using a very small amount of radiation to estimate bone mineral density (BMD); this can be compared with age-matched controls to give a $Z$-score or, when compared with peak bone mass achieved in young adults, a $T$-score (5)

Community health nurse provide elderly people with health educations about ways to get more calcium. Eat foods such as low-fat milk, yogurt, cheese, sardines, soy products, and collard greens. Many foods such as orange juice, breakfast bars, and cereals have calcium added (6).

Osteoporosis has its influences on quality of the life that reflects on of physical, psychological and social functions for patient with osteoporosis. Physical changes such as muscle weakness and increased spine kyphosis leading to vertebral fracture and poor vertebral fracture, balance central or hip fracture are usually associated with significant morbidity and mortality of elderly. (6)

.General Guidelines for Managing Osteoporosis maintain healthy life style include: Eat a healthful diet, Exercise regularly, Don't smoke, Watch alcohol and caffeine use, Prevent falls, and Eat a Healthful Diet: Good nutrition is vital for normal growth and development (4).

\section{Significance of the Study}

Annually affect osteoporosis 200 million women and 8.9 million clients in the world had fracture, this fracture increase mortality and morbidity by decrease client quality of life due to prolonged hospital admission and the client mostly treated by surgical intervention so increasing the cost of medical management. In Egypt, osteoporosis is a major health problem so, many studies about osteoporosisdocumented that $53.9 \%$ of postmenopausal women have osteopenia while $28.4 \%$ have got osteoporosis and $21.9 \%$ have got osteoporosis among men (8).

Aim of the study: to assess of life style for elderly with osteoporosis in Beni-Suef university hospital.

Research questions: What is the life style for elderly with osteoporosis in Benisuief University Hospital?

\section{Subjects and Methods}

Research Design: A descriptive design was used to achieve the aim of the current study. 
Setting: This study was conducted in the following: outpatient orthopedic clinic and rheumatology clinic at Beni-Suef University Hospital.

Subjects: Convenient sample was used for this study; include all available elderly patients in outpatient clinic of orthopedic \& rehabilitation clinic at Beni-Suef University Hospital.

\section{Data Collections Tools}

Three tools were used in the current study as the following:

1. Patient assessment tool: This tool was developed and filled by the investigator to suite the study aim. It includes two parts: Demographic data \& Medical history data.

Part (I): Demographic Data: It used to assess demographic characteristic of the studied patients as age, gender and educational level ... etc.

Part (II): Medical history Data: It used to collect data regarding present and past medical history, Family history and regular medication patients on.

2. Patients' knowledge assessment tool: used by the investigator for assessment of patient's Knowledge regarding osteoporosis as definition of osteoporosis, risk factors, symptoms, complication, preventive measures, importance of good nutrition and exercise.

\section{Life style assessment tool:}

This tool was used by the investigator to assess patient's life style as (balanced diet, exercise, exposure to the sun ... etc.)

\section{Data Collection Procedure}

Data were collected in six months from June (2020) to the end of November (2020). Data were collected by the investigator 4 hours per day, 3 days per week, at day shifts in the previous mentioned settings.

Firstly, subject's demographic characteristics such as age and gender and medical data were recorded in a data collection form. Then, the investigator by using Patients' knowledge assessment tool asking patient to assess patient's Knowledge regarding osteoporosis as definition of osteoporosis, risk factors, symptoms, complication, preventive measures, importance of good nutrition and exercise. Later in, the investigator assessed the patient's life style by using Life style assessment tool by asking questions regarding balanced diet, exercise, exposure to the sun ... etc.

\section{Pilot Study}

A pilot study was carried out on $10 \%$ of total study subjects (6) to test the clarity, applicability, feasibility and relevance of the tools used and to determine the needed time for the application of the study tools. The patients who were included in the pilot study excluded from the sample because minor modification was done after conducting pilot study 


\section{Ethical Consideration}

The ethical research considerations in this study included the following:

1. Approval of the study protocol was obtained from Ethical Committee in the Faculty of Nursing at Beni-seuf University before starting the study. The investigator clarified the objective and aim of the study to the patients included in the study and obtained written consent from them to participate.

2. The investigator assured maintaining anonymity and confidentiality of the subject data and patient safety assured during the study.

3. Patients were informed that they allowed choosing to participate or not in the study and that they have the right to withdraw from the study at any time without giving any reasons.

\section{Results}

Table (1) Percentage distribution of demographic characteristics of elderly people with osteoporosis $(n=72$ patients).

\begin{tabular}{|l|c|c|}
\hline \multicolumn{1}{|c|}{ Demographic characteristics } & No. & \% \\
\hline 1. Age & & \\
\hline$-\quad$ 70-75 year & 44 & 61.1 \\
\hline$-\quad>85$ years & 17 & 23.6 \\
\hline 2. Gender & 11 & 15.3 \\
\hline$-\quad$ Male & 51 & 70.8 \\
\hline$-\quad$ Female & 21 & 29.2 \\
\hline 3. Marital status & & \\
\hline$-\quad$ Single & 4 & 5.6 \\
\hline$-\quad$ Married & 17 & 23.6 \\
\hline$-\quad$ Widowed & 39 & 54.2 \\
\hline$-\quad$ Divorced & 12 & 16.7 \\
\hline 4. Residence & 40 & \\
\hline$-\quad$ Rural & 32 & 44.5 \\
\hline$-\quad$ Urban & & \\
\hline 5. Living with & 14 & 19.4 \\
\hline$-\quad$ Alone & 39 & 54.2 \\
\hline$-\quad$ Family & 19 & 26.4 \\
\hline$-\quad$ With his relatives & 13 & \\
\hline 6. Educational level & 30 & 41.7 \\
\hline$-\quad$ Illiterate & 22 & 30.6 \\
\hline$-\quad$ Read and write & 7 & 9.7 \\
\hline$-\quad$ Secondary education & & \\
\hline$-\quad$ Above secondary education & & \\
\hline & & \\
\hline
\end{tabular}

Table (1): shows that $(61.1 \%)$ of elderly people with osteoporosis had $60-75$ year, $(70.8 \%)$ of them were male. $(54.2 \%)$ of elderly people with osteoporosis were widowed, $(55.5 \%)$ of them were lived in rural. (54.2\%) of elderly people with osteoporosis were living with their family, $(41.7 \%)$ of them were read and write. 
Table (2): Percentage distribution of past history of elderly people with osteoporosis $(n=72$ patients).

\begin{tabular}{|c|c|c|}
\hline Elderly history & No. & $\%$ \\
\hline \multicolumn{3}{|l|}{ 1. Elderly chronic diseases } \\
\hline - $\quad$ Rheumatoid arthritis & 14 & 19.4 \\
\hline - $\quad$ Liver disease & 17 & 23.6 \\
\hline - Digestion dysfunction disease & 22 & 30.6 \\
\hline - $\quad$ Thyroid problems & 2 & 2.8 \\
\hline - $\quad$ Bleeding from the gums & 3 & 4.2 \\
\hline - Epilepsy & 1 & 1.4 \\
\hline - Insulin-dependent diabetes & 13 & 18.1 \\
\hline \multicolumn{3}{|l|}{ 2. Family history of chronic diseases } \\
\hline - No history of chronic diseases & 11 & 15.3 \\
\hline - Rheumatoid arthritis & 23 & 31.9 \\
\hline - $\quad$ Liver disease & 6 & 8.3 \\
\hline - Digestion dysfunction disease & 15 & 20.8 \\
\hline - Thyroid problems & 1 & 1.4 \\
\hline - Bleeding from the gums & 5 & 6.9 \\
\hline - Epilepsy & 2 & 2.8 \\
\hline - Insulin-dependent diabetes & 9 & 12.5 \\
\hline \multicolumn{3}{|l|}{ 3. Patients previous history of fractures } \\
\hline - Yes & 24 & 66.7 \\
\hline$-\mathrm{No}$ & 48 & 33.3 \\
\hline \multicolumn{3}{|l|}{ 4. Family Previous history of fractures } \\
\hline - Yes & 18 & 25 \\
\hline- No & 54 & 75 \\
\hline \multicolumn{3}{|l|}{ - If yes what is the relation with you $(n=18)$} \\
\hline$\circ$ Mother & 7 & 38.8 \\
\hline O Father & 3 & 16.7 \\
\hline o Brother/Sister & 2 & 11.2 \\
\hline$\circ$ Grandfather/grandmother & 6 & 33.3 \\
\hline \multicolumn{3}{|l|}{ 5. Regular medication } \\
\hline - No regular medications & 33 & 45.8 \\
\hline - Cortisone & 24 & 33.3 \\
\hline - $\quad$ Medications against convulsions (epilepsy) & 1 & 1.4 \\
\hline - $\quad$ Anticoagulant (drugs) & 6 & 8.3 \\
\hline - Hormones drugs & 8 & 11.1 \\
\hline
\end{tabular}

Table 2: reveals that $(30.6 \%)$ of elderly people with osteoporosis had digestion dysfunction disease regarding Elderly chronic diseases. (31.9\%) of them had Rheumatoid arthritis regarding Family history of chronic diseases. (66.7\%) of elderly people with osteoporosis had previous history of fractures. (75\%) of them hadn't Family Previous history of fractures. (45.8\%) of elderly people with osteoporosis hadn't regular medications. 
Table (3) Percentage distribution of Patients' general knowledge about osteoporosis ( $\mathrm{n}=72$ patients).

\begin{tabular}{|c|c|c|c|c|}
\hline \multirow[t]{2}{*}{ Items } & \multicolumn{2}{|c|}{ Correct } & \multicolumn{2}{|c|}{ Incorrect } \\
\hline & No. & $\%$ & No. & $\%$ \\
\hline $\begin{array}{l}\text { 1. Importance of good nutrition for } \\
\text { osteoporosis patients }\end{array}$ & 38 & 52.8 & 34 & 47.2 \\
\hline $\begin{array}{l}\text { 2. Dietary elements of good nutrition for } \\
\text { osteoporosis patients }\end{array}$ & 16 & 22.2 & 56 & 77.8 \\
\hline 3. Importance of calcium & 12 & 16.7 & 60 & 83.3 \\
\hline 4. Importance of vitamin D & 24 & 33.3 & 48 & 66.7 \\
\hline 5. Importance of enough protein & 28 & 38.9 & 44 & 61.1 \\
\hline 6. Sources of calcium & 44 & 61.1 & 28 & 38.9 \\
\hline 7. Sources of vitamin D & 37 & 51.4 & 35 & 48.6 \\
\hline 8. The optimum amount of daily calcium & 15 & 20.8 & 57 & 79.2 \\
\hline 9. The optimum amount of daily vitamin $\mathrm{D}$ & 27 & 37.5 & 45 & 62.5 \\
\hline 10. Sources of vitamin K & 21 & 29.2 & 51 & 70.8 \\
\hline 11. Sources of protein & 36 & 50 & 36 & 50 \\
\hline
\end{tabular}

Table 3: illustrates that (68.1\%) of elderly people with osteoporosis had correct answer about Dietary risk factors of osteoporosis, and Preventive measures of osteoporosis. While, $(72.2 \%)$ of elderly people with osteoporosis had incorrect answer about Complications of osteoporosis

\section{Figure (1): Percentage distribution of patients' total knowledge regarding osteoporosis $(n=72$ patients}

\section{Total Patients' Knowledge}

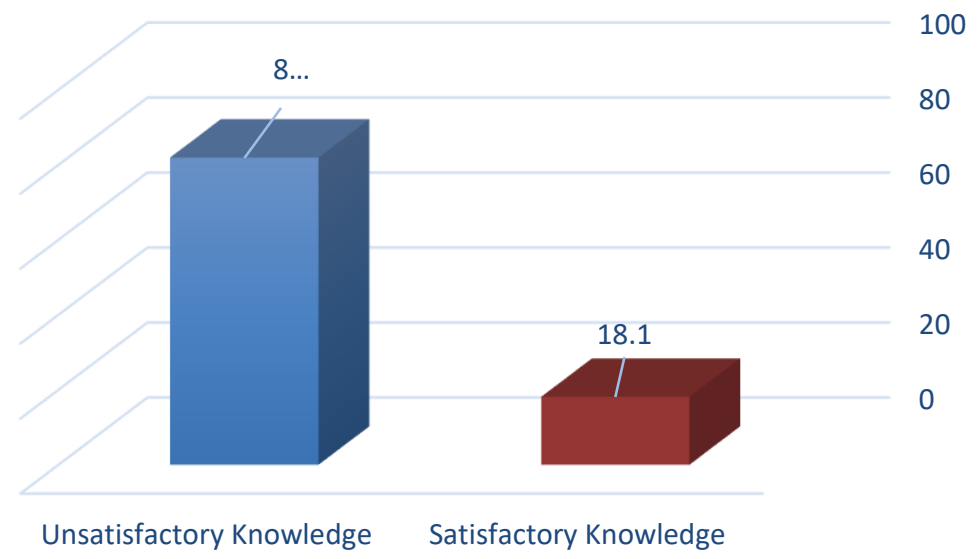

Figure (1): reveals that $(81.9 \%)$ of elderly people with osteoporosis had unsatisfactory total knowledge regarding osteoporosis. While, (18.1\%) of them had satisfactory total knowledge regarding osteoporosis. 
Figure (2) Percentage distribution of total lifestyle scores of elderly patients with osteoporosis $(n=72$ patients).

\section{Total life style scores}

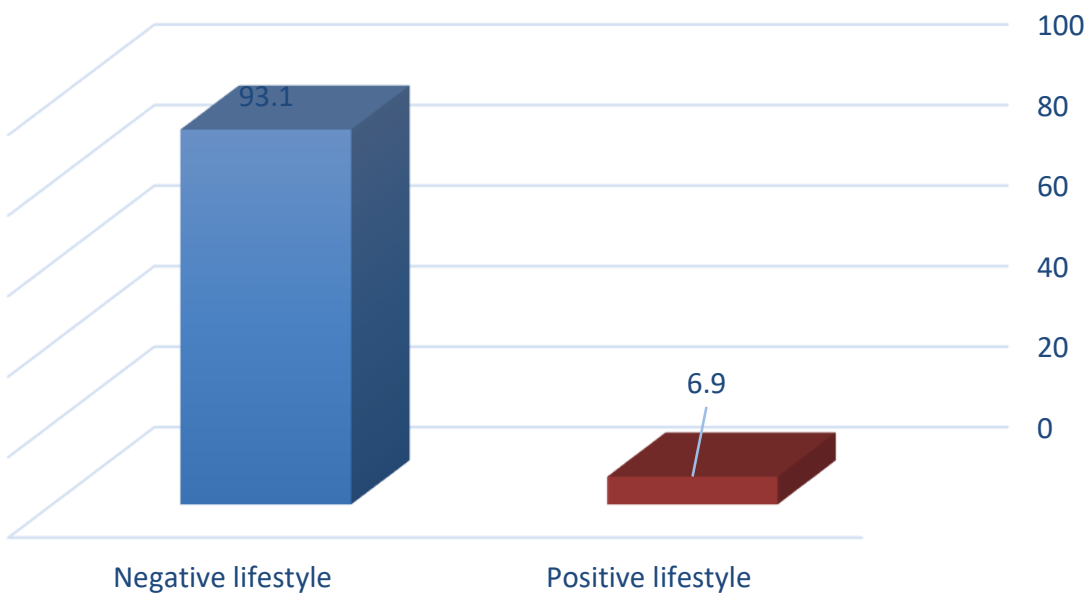

Figure 2: reveals that $(93.1 \%)$ of elderly people with osteoporosis had negative total lifestyle scores with osteoporosis. While, $(6.9 \%)$ of them had positive total lifestyle scores with osteoporosis.

Table (4) The relation between patients' demographic characteristics and their total knowledge.

\begin{tabular}{|c|c|c|c|c|c|c|c|}
\hline \multirow[t]{2}{*}{$\begin{array}{l}\text { Demographic } \\
\text { characteristics }\end{array}$} & \multirow[t]{2}{*}{ NO } & \multicolumn{2}{|c|}{$\begin{array}{l}\text { Satisfactory } \\
\text { knowledge }\end{array}$} & \multicolumn{2}{|c|}{$\begin{array}{c}\text { Unsatisfactory } \\
\text { knowledge }\end{array}$} & \multirow[t]{2}{*}{$\mathbf{X}^{2}$} & \multirow[t]{2}{*}{$\begin{array}{c}\text { P- } \\
\text { Value }\end{array}$} \\
\hline & & NO. & $\%$ & NO. & $\%$ & & \\
\hline \multicolumn{6}{|l|}{ Age } & \multirow[t]{4}{*}{3.26} & \multirow[t]{4}{*}{$.039 *$} \\
\hline$-60-75$ year & 44 & 9 & 12.5 & 35 & 48.6 & & \\
\hline$-75-85$ year & 17 & 2 & 2.7 & 15 & 20.8 & & \\
\hline$->85$ years & 11 & 2 & 2.7 & 9 & 12.5 & & \\
\hline \multicolumn{6}{|l|}{ Gender } & \multirow[t]{3}{*}{3.63} & \multirow[t]{3}{*}{$.007 *$} \\
\hline - Male & 51 & 8 & 11.1 & 43 & 59.7 & & \\
\hline - Female & 21 & 5 & 6.9 & 16 & 22.2 & & \\
\hline \multicolumn{6}{|l|}{ Marital status } & \multirow[t]{5}{*}{1.24} & \multirow[t]{5}{*}{.587} \\
\hline - Single & 4 & 0 & 0 & 4 & 5.6 & & \\
\hline - Married & 17 & 4 & 5.6 & 13 & 18.1 & & \\
\hline - Widowed & 39 & 7 & 9.7 & 32 & 44.5 & & \\
\hline - Divorced & 12 & 2 & 2.7 & 10 & 13.9 & & \\
\hline \multicolumn{6}{|l|}{ Residence } & \multirow[t]{3}{*}{.285} & \multirow[t]{3}{*}{.434} \\
\hline - Rural & 40 & 9 & 12.5 & 31 & 43.4 & & \\
\hline - Urban & 32 & 4 & 5.6 & 28 & 38.9 & & \\
\hline \multicolumn{6}{|l|}{ Educational level } & \multirow[t]{5}{*}{2.14} & \multirow[t]{5}{*}{. $.028 *$} \\
\hline - Illiterate & 13 & 2 & 2.7 & 11 & 15.3 & & \\
\hline - Read and write & 30 & 7 & 9.7 & 23 & 31.9 & & \\
\hline - Secondary education & 22 & 2 & 2.7 & 20 & 27.8 & & \\
\hline - Above secondary education & 7 & 2 & 2.7 & 5 & 6.9 & & \\
\hline
\end{tabular}

(*) Statistically significant at p-value $<0.05$. 
Table 4: reveals that there was a statistically significant relation between patients' total knowledge and their age, residences, and educational level. While, there was no statistically significant relation between patients' total knowledge and their gender, and marital status.

Table (5) The relation between patients' demographic characteristics and their lifestyle

\begin{tabular}{|c|c|c|c|c|c|c|c|}
\hline \multirow[t]{2}{*}{$\begin{array}{c}\text { Demographic } \\
\text { characteristics }\end{array}$} & \multirow[t]{2}{*}{ NO } & \multicolumn{2}{|c|}{$\begin{array}{l}\text { Positive } \\
\text { lifestyle }\end{array}$} & \multicolumn{2}{|c|}{$\begin{array}{l}\text { Negative } \\
\text { lifestyle }\end{array}$} & \multirow[t]{2}{*}{$\mathbf{X}^{2}$} & \multirow[t]{2}{*}{$\begin{array}{c}\text { P- } \\
\text { Value }\end{array}$} \\
\hline & & NO. & $\%$ & NO. & $\%$ & & \\
\hline \multicolumn{6}{|l|}{ Age } & \multirow[t]{4}{*}{3.41} & \multirow[t]{4}{*}{$.001 *$} \\
\hline$-60-75$ year & 44 & 3 & 4.2 & 41 & 56.9 & & \\
\hline$-75-85$ year & 17 & 0 & 0 & 17 & 23.6 & & \\
\hline - >85 years & 11 & 2 & 2.8 & 9 & 12.5 & & \\
\hline \multicolumn{6}{|l|}{ Gender } & \multirow[t]{3}{*}{.219} & \multirow[t]{3}{*}{.543} \\
\hline - Male & 51 & 4 & 5.6 & 47 & 65.3 & & \\
\hline - Female & 21 & 1 & 1.4 & 20 & 27.8 & & \\
\hline \multicolumn{6}{|l|}{ Marital status } & \multirow[t]{5}{*}{1.83} & \multirow[t]{5}{*}{$.014^{*}$} \\
\hline - Single & 4 & 0 & 0 & 4 & 5.6 & & \\
\hline - Married & 17 & 2 & 2.8 & 15 & 20.8 & & \\
\hline - Widowed & 39 & 3 & 4.2 & 36 & 50 & & \\
\hline - Divorced & 12 & 0 & 0 & 12 & 16.7 & & \\
\hline \multicolumn{6}{|l|}{ Residence } & \multirow[t]{3}{*}{2.35} & \multirow[t]{3}{*}{$.016^{*}$} \\
\hline - Rural & 40 & 3 & 4.2 & 37 & 51.4 & & \\
\hline - Urban & 32 & 2 & 2.8 & 30 & 41.7 & & \\
\hline \multicolumn{6}{|l|}{ Educational level } & \multirow[t]{5}{*}{3.71} & \multirow[t]{5}{*}{$.037 *$} \\
\hline - Illiterate & 13 & 0 & 0 & 13 & 18.1 & & \\
\hline - Read and write & 30 & 2 & 2.8 & 28 & 38.9 & & \\
\hline $\begin{array}{l}\text { - Secondary } \\
\text { education }\end{array}$ & 22 & 2 & 2.8 & 20 & 27.8 & & \\
\hline $\begin{array}{l}\text { - Above secondary } \\
\text { education }\end{array}$ & 7 & 1 & 1.4 & 6 & 8.3 & & \\
\hline
\end{tabular}

(*) Statistically significant at p-value $<0.05$.

Table 5: illustrates that there was a statistically significant relation between patients' lifestyle and their age, marital status, residences, and educational level. While, there was no statistically significant relation between patients' total knowledge and their gender. 
Table (6) Correlation between patients' total knowledge and their lifestyle

\begin{tabular}{|l|l|c|c|}
\hline \multicolumn{2}{|l|}{} & $\begin{array}{c}\text { Total } \\
\text { knowledge }\end{array}$ & $\begin{array}{c}\text { Total lifestyle } \\
\text { scores }\end{array}$ \\
\hline Total knowledge & $\mathrm{R}$ & 1 & .289 \\
\cline { 2 - 4 } & $\mathrm{P}$ & - & $.000^{* *}$ \\
\hline Total lifestyle scores & $\mathrm{R}$ & .289 & 1 \\
\cline { 2 - 4 } & $\mathrm{P}$ & $.000^{* *}$ & - \\
\hline
\end{tabular}

$(* *)$ Highly statistically significant at $\mathrm{p}$-value $<0.05$.

Table 6: shows that there was a positive correlation between patients' total knowledge and their lifestyle

\section{Discussion}

Older people are a rapidly growing proportion of the world's population, people are living longer, but that does not necessarily mean that they are living healthier. The increase in our aging population presents many opportunities and also several public health challenges that we need to prepare for. Osteoporosis has partnered with census to provide the best possible data so that we can better understand the course and implications of population aging (9).

Osteoporosis is a chronic progressive disease of multi factorial. It is the most common metabolic bone disease in the United States. It has been most frequently recognized in elderly white women, although it does occur in men and women, all races, and all age groups. As one age, bone mass tends to decline due to a variety of factors. Osteoporosis which is an early warning sign, signals an imbalance in the remodeling signal. Too much bone is broken down and too little new bone is built back this result to brittle bones which are prone to fracture. A combination of causes is often to blame for bone loss (10).

Healthy life style a guide to elderly care which the mind and the body do change over time and things don't always work as they should, but much of this can be prevented by following a healthy life style as stop smoking - moderate alcohol consumption- take exercise, healthy diet, stay mental active, socialize with other get out in fresh air, make sure that your home is safe positive thinking, life style modification elderly people with osteoporosis through correct, balance diet, diet contain micronutrients as calcium, magnesium, phosphorus, sodium, potassium, various vitamin and protein and fatty acid are important element to prevent bone fracture, vitamin D help bone to absorb calcium (11).

Regarding elderly people's age, the current study showed that more than nearly two thirds of elderly people with osteoporosis had $60-75$ year. From the 
researcher opinion, this result may be due to all participants were elderly people. Also, this result was supported with (12) who conducted entitled "Performance of risk assessment tools for predicting osteoporosis in south Indian rural elderly men" and found that majority of participants were male, and lived in rural area, more than two thirds elderly people with osteoporosis had $60-75$ year

Concerning elderly people's gender, the current study showed that more than two thirds of them were male. From the researcher opinion, this result may be due to majority of participants were male. This result was in agreement with (13) who conducted entitled "clinical guideline for the prevention and treatment of osteoporosis" and found that more than half of participants were male. Conversely, this result was in disagreement with (14) who conducted entitled "Postmenopausal osteoporosis: assessment and management" and found that more than half of participants were female.

Also, elderly people's marital status, the current study showed that more than half of elderly people with osteoporosis were widowed. From the researcher opinion, this result may be due to elderly people in this age loss their wives. This result was in agreement with (15) who found that three quarters of participants were widowed. Conversely, this result was in disagreement with (16) who conducted entitled "Determinants of imminent fracture risk in postmenopausal women with osteoporosis" and found that more than half of elderly people with osteoporosis were married.

In addition to, elderly people's residence, the current study showed that more than half of elderly people with osteoporosis lived in rural, and lived with their family. From the researcher opinion, this result may be due to participants had strong contact with their families. This result was in agreement with (13) who found that more than two thirds of them were lived with their family. Also, this result was supported with (12) found that majority of participants were male, and lived in rural area.

Regarding distribution of past history of elderly people with osteoporosis, the current study revealed that nearly one third of elderly people with osteoporosis had digestion dysfunction disease regarding elderly chronic disease, had rheumatoid arthritis about Family history of chronic diseases. More than two thirds of elderly people with osteoporosis had previous history of fractures. Three quarters of them hadn't Family Previous history of fractures. Nearly half of elderly people with osteoporosis hadn't regular medications. From the researcher opinion, this result may be due to elderly people suffering from osteoporosis that effect on their life style.

This result was in agreement with (14) who sated that three quarters of participants had chronic diseases and they were competent with their medications. Conversely, this result was in disagreement with (15) who found that more than half of elderly people with osteoporosis hadn't previous history of fractures

Regarding distribution of Patients' general knowledge about osteoporosis, the current study illustrated that more than two thirds of elderly people with osteoporosis had satisfactory knowledge about Dietary risk factors of osteoporosis, and Preventive measures of osteoporosis. While, nearly three quarters of elderly people with 
osteoporosis had unsatisfactory knowledge about Complications of osteoporosis. From the researcher opinion, this result may be due to elderly people with osteoporosis were adapted with their disease and keep on healthy diet to avoid complications of their disease.

This result was accordance with (17) who conducted entitled "Screening for osteoporosis to prevent fractures: US Preventive Services Task Force recommendation statement" and found that more than two thirds of participants had good knowledge about osteoporosis. Conversely, this result was in disagreement with (18) who conducted entitled "Prevalence of osteoporosis and low bone mass among Puerto Rican older adults" and found that more than half of participants had unsatisfactory knowledge about osteoporosis.

Regarding distribution of total lifestyle scores of elderly patients with osteoporosis, the current study revealed that majority of elderly people with osteoporosis had negative total lifestyle scores with osteoporosis. While, more than two thirds of them had positive total lifestyle scores with osteoporosis. From the researcher point of view, this result may be due to elderly people weren't interested with their life style.

This result was supported with (19) who conducted entitled "The Lifting Intervention For Training Muscle and Osteoporosis Rehabilitation for Men" and found that majority of elderly people with osteoporosis had negative total lifestyle scores with osteoporosis. Also, this result was accordance with (20). who conducted entitled "Diagnosis, assessment and management of osteoporosis" and found that half of elderly people with osteoporosis had positive total lifestyle scores with osteoporosis.

Regarding relation between patients' demographic characteristics and their total knowledge, the current study revealed that there was a statistically significant relation between patients' total knowledge and their age, residences, and educational level. While, there was no statistically significant relation between patients' total knowledge and their gender, and marital status.

This result was supported with (21) who conducted entitled "A Comparative Study of Current Methods and Recent Advances in the Diagnosis and Assessment of Osteoporosis" and found that there was a statistically significant relation between patients' total knowledge and their demographic characteristics. Conversely, this result was disagreement with (22) who conducted entitled "Patient education in osteoporosis prevention" and found that there was highly statistically significant relation between patients' total knowledge and their demographic characteristics.

Regarding relation between patients' demographic characteristics and their lifestyle, the current study illustrated that there was a statistically significant relation between patients' lifestyle and their age, marital status, residences, and educational level. While, there was no statistically significant relation between patients' total knowledge and their gender.

This result was agreement with (23). who conducted entitled "Proposal of an adapted physical activity exercise protocol for women with osteoporosis" and found 
that there was no statistically significant relation between patients' lifestyle and their demographic characteristics. Conversely, this result was disagreement with (24) who conducted entitled "Education and exercise program improves osteoporosis knowledge and changes calcium and vitamin D dietary intake in community dwelling elderly" and found that there was no statistically significant relation between patients' lifestyle and their demographic characteristics.

Regarding correlation between patients' total $\mathrm{k}$ [nowledge and their lifestyle, the current study showed that there was a positive correlation between patients' total knowledge and their lifestyle

This result was agreement with (25). who conducted entitled "The prevalence of osteoporosis in China" and found that there was a positive correlation between patients' total knowledge and their lifestyle. Conversely, this result was disagreement with (26). who conducted entitled "Knowledge and health beliefs of elderly women toward osteoporosis in Mansoura" and found that there was a negative correlation between patients' total knowledge and their lifestyle.

\section{Conclusion}

Based on the finding of the current study it can be concluded that, majority of elderly people with osteoporosis had unsatisfactory total knowledge regarding osteoporosis. Majority of elderly people with osteoporosis had negative total lifestyle scores with osteoporosis. There was a positive correlation between patients' total knowledge and their lifestyle.

\section{Recommendations}

In the light of results of the present study, the following recommendations were suggested:

1. Periodic assessment for elderly with osteoporosis in Beni-Suef university hospital, Help elderly to enhance life style in Beni-Suef university hospital.

2. Provide training for nurses with elderly with osteoporosis in Beni-Suef university hospital to support patients.

\section{References}

1) Yang, T. L., Shen, H., Liu, A., Dong, S. S., Zhang, L., Deng, F. Y., ... \& Deng, H. W. (2020). A road map for understanding molecular and genetic determinants of osteoporosis. Nature Reviews Endocrinology, 16(2), 91-103.

2) Girgis, C. M., \& Clifton-Bligh, R. J. (2020). Osteoporosis in the age of COVID19. Osteoporosis International, 31(7), 1189-1191.

3) Anagnostis, P., Gkekas, N. K., Potoupnis, M., Kenanidis, E., Tsiridis, E., \& Goulis, D. G. (2019). New therapeutic targets for osteoporosis. Maturitas, 120, 1-6.

4) Kanis, J. A. (2019). Diagnosis and clinical aspects of osteoporosis. In Pocket reference to osteoporosis (pp. 11-20). Springer, Cham.

5) Clynes, M. A., Harvey, N. C., Curtis, E. M., Fuggle, N. R., Dennison, E. M., \& Cooper, C. (2020). The epidemiology of osteoporosis. British medical bulletin, 133(1), 105 
6) Aspray, T. J., \& Hill, T. R. (2019). Osteoporosis and the ageing skeleton. Biochemistry and Cell Biology of Ageing: Part II Clinical Science, 453-476.

7) Kanis, J. A., Cooper, C., Rizzoli, R., \& Reginster, J. Y. (2019). European guidance for the diagnosis and management of osteoporosis in postmenopausal women. Osteoporosis International, 30(1), 3-44.

8) Mansour M and Al agamy. (2018) . "Effect of health education intervention about osteoporosis on knowledge and dietary hapits of woman employee"; published. Fayoum University. Faculty of Nursing. P 29:37

9) .Alonge, T. O., Adebusoye, L. A., Ogunbode, A. M., Olowookere, O. O., Ladipo, M. A., Balogun, W. O., \& Okoje-Adesomoju, V. (2017): Factors associated with osteoporosis among older patients at the Geriatric Centre in Nigeria: a cross-sectional study. South African Family Practice, 59(3), 87-93.

10) Walker, J. (2021). Osteoporosis and fragility fractures: risk assessment, management and prevention. Nursing older people, 33(1).

11) Mehrabadi, E., Pakgohar, M., Asadi, S., \& Haghani, H. (2017). Lifestyle of elderly people with osteoporosis and its related factors. Iranian Journal of Ageing, 12(2), $132-145$.

12) Satyaraddi, A., Shetty, S., Kapoor, N., Cherian, K. E., Naik, D., Thomas, N., \& Paul, T. V. (2017). Performance of risk assessment tools for predicting osteoporosis in south Indian rural elderly men. Archives of osteoporosis, 12(1), 35.

13) Compston, J., Cooper, A., Cooper, C., Gittoes, N., Gregson, C., Harvey, N., ... \& Vine, N. (2017): UK clinical guideline for the prevention and treatment of osteoporosis. Archives of osteoporosis, 12(1), 43.

14) Rizzoli, M. (2015): Complication of Osteoporosis. Endocrinol Metab Clin North Am 27, 365-369

15) Rizzoli, R. (2018). Postmenopausal osteoporosis: assessment and management. Best Practice \& Research Clinical Endocrinology \& Metabolism, 32(5), 739-757.

16) Barron, R. L., Oster, G., Grauer, A., Crittenden, D. B., \& Weycker, D. (2020): Determinants of imminent fracture risk in postmenopausal women with osteoporosis. Osteoporosis International, 31(11), 2103-2111.

17) Curry, S. J., Krist, A. H., Owens, D. K., Barry, M. J., Caughey, A. B., Davidson, K. W., ... \& US Preventive Services Task Force. (2018): Screening for osteoporosis to prevent fractures: US Preventive Services Task Force recommendation statement. Jama, 319(24), 2521-2531.

18) Noel, S. E., Mangano, K. M., Griffith, J. L., Wright, N. C., Dawson-Hughes, B., \& Tucker, K. L. (2018). Prevalence of osteoporosis and low bone mass among Puerto Rican older adults. Journal of Bone and Mineral Research, 33(3), 396-403.

19) Harding, A. T., Weeks, B. K., Watson, S. L., \& Beck, B. R. (2017): The Lifting Intervention For Training Muscle and Osteoporosis Rehabilitation for Men trial: protocol for a semirandomised controlled trial of supervised targeted exercise to reduce risk of osteoporotic fracture in older men with low bone mass. BMJ open, 7(6), e014951.

20) Blackie, R. (2020): Diagnosis, assessment and management of osteoporosis. Prescriber, 31(1), 14-19.

21) Shirzadfar, H., \& Gordoghli, N. (2020). A Comparative Study of Current Methods and Recent Advances in the Diagnosis and Assessment of Osteoporosis. Recent Research in Endocrinology and Metabolic Disorder, 2(1), 3-17.

22) Vennedey, V., Morfeld, J. C., Müller, D., Pieper, D., \& Stock, S. (2017). Patient education in osteoporosis prevention: a systematic review focusing on methodological quality of randomised controlled trials. Osteoporosis International, 28(6), 1779-1803.

23) Marini, S., Leoni, E., Raggi, A., Sanna, T., Malavolta, N., Angela, B., ... \& Dallolio, L. (2019). Proposal of an adapted physical activity exercise protocol for women with 
osteoporosis-related vertebral fractures: a pilot study to evaluate feasibility, safety, and effectiveness. International journal of environmental research and public health, 16(14), 2562.

24) Park, K. S., Yoo, J. I., Kim, H. Y., Jang, S., Park, Y., \& Ha, Y. C. (2017). Education and exercise program improves osteoporosis knowledge and changes calcium and vitamin D dietary intake in community dwelling elderly. BMC Public Health, 17(1), $1-8$.

25) Zeng, Q., Li, N., Wang, Q., Feng, J., Sun, D., Zhang, Q \& Cheng, X. (2019). The prevalence of osteoporosis in China, a nationwide, multicenter DXA survey. Journal of Bone and Mineral Research, 34(10), 1789-1797.

26) El-Masry, R., Elkhawaga, G., El-Gilany, A. H., \& Alam, R. R. (2018): Knowledge and health beliefs of elderly women toward osteoporosis in Mansoura, Egypt. Progress in Medical Sciences, 2(2), 27-3. 